\title{
Breast Cancer pN1c TNM Finding v8
}

National Cancer Institute

\section{Source}

National Cancer Institute. Breast Cancer pN1C TNM Finding v8. NCI Thesaurus. Code C139437.

Breast cancer with pN1a and pN1b combined. (from AJCC 8th Ed.) 